\title{
$\mathrm{JGB}$ 첨가제에 의한 동박의 미세구조변화와 전기적 특성 우태규 ${ }^{1,2}$ - 박일송 3 ,* \\ 1전북대학교 유연인쇄전자공학과 \\ 2전북대학교 로스알라모스연구소-전북대학교 한국공학연구소 \\ 3전북대학교 신소재공학부
}

\section{Effects of JGB Additives on the Microstructures and Electrical Properties of Electroplated Copper Foil}

\author{
Tae-Gyu Woo ${ }^{1,2}$ and Il-Song Park ${ }^{3, *}$ \\ ${ }^{1}$ Graduate School of Flexible and Printable Electronics, Jeonbuk National University, Jeonbuk 54896, Republic of Korea \\ ${ }^{2}$ LANL-CBNU Engineering Institute Korea, Jeonbuk National University, Jeonbuk 54896, Republic of Korea \\ ${ }^{3}$ Division of Advanced Materials Engineering, Research Center for Advanced Materials Development, \\ Jeonbuk National University, Jeonbuk 54896, Republic of Korea
}

\begin{abstract}
Extremely thin film high quality copper foil is required to ensure high performance in electronics and slimness in secondary batteries. During the electroplating of copper foil, Janus Green B(JGB) and Collagen were introduced as additives to the electrolytes to study their effects. The structural and electrical properties of the electroplated copper foil were evaluated. When each additive was added individually, the potential was increased. Specifically, the potential of the group with $30 \mathrm{ppm}$ added collagen was about $27 \%$ higher rather than the non-additive group. When $\mathrm{Cl}^{-}$ions and MPSA(3-mercapto-1-propane sulfonic acid) were added to the electrolytes without collagen and JGB, the surface roughness(Rz) increased by about $136 \%$ to $2.24 \mu \mathrm{m}$ compared to the non-additive group. This was the highest value among all groups. However, a uniform layer with a surface roughness value below $0.3 \mu \mathrm{m}$ was formed when less than $30 \mathrm{ppm}$ and $10 \mathrm{ppm}$ collagen and JGB were added, respectively, to the electrolyte. The direction of crystal growth with the JGB additives tended to go forward to the (220) direction, and the crystal size was reduced by $10 \sim 27 \%$ compared to the non-additive group. The addition of Collagen is necessary to reduce the difference in resistivity of the shiny layer and right matte layer. JGB additives were required to reduce the deviation in grain size. The results confirmed that the accelerators, inhibitors and leveler need to be properly added to form a copper plating layer with low surface roughness and to reduce differences in crystal texture of the shiny layer and right matte layer. Copper foil can be safely and uniformly deposited from electrolytes with JGB below $10 \mathrm{ppm}$ and collagen below $30 \mathrm{ppm}$.
\end{abstract}

(Received December 4, 2020; Accepted December 14, 2020)

Keywords: organic additive, surface roughness, electrical property, electroplating, copper foil

\begin{abstract}
1. 서 론
최근 전자제품의 고성능화로 회로가 복잡해짐에 따라 전 자회로의 미세패턴화가 필요하며 리튬 이온 전지의 슬림화 로 리튬 이온 전지의 음극재료로 사용되는 동박의 극박화,
\end{abstract}

- 우태규·박일송: 교수

*Corresponding Author: Il-Song Park

[Tel: +82-63-270-2294, E-mail: ilsong@jbnu.ac.kr]

Copyright (C) The Korean Institute of Metals and Materials
품질 향상 및 생산성 향상 요구가 커지고 있다. 이러한 용 도로 사용되는 동박은 압연방법이나 전해도금방법으로 제 조된다. 전해도금 방식은 장길이 와인딩으로 대량생산이 가 능하고, 압연박보다 생산 폭이 넓기 때문에 상대적으로 저 렴한 가격, 낮은 전기저항, 우수한 열 전도성 등의 장점을 가지고 있어 정밀도가 요구되는 부분에서 전해동박이 주로 사용되고 있다 [1-7].

전해도금법을 이용하여 동박 제조 시 표면 형상, 결정구 
조 및 전기적 특성에 미치는 인자로는 유속, 음극 전압, 온도, 전류밀도, 첨가제, 전해액 순도, 전극 간격 등 매우 다양하다 [8-12]. 그 중에서도 전해액의 조성 선정은 전해 도금 공정에서 배선재료의 기본 물성을 결정하는 중요한 요소이다. 또한 생산량을 증대시키기 위해서는 높은 전류 밀도에 적용 가능한 첨가제 개발이 절실하다. 전해액내에 첨가되는 적은양의 유기 첨가제는 전해동박 구조에 영향을 미치며, 높은 휘도를 갖는 균일한 도금층의 형성을 촉진시 키고 전착의 기계적 특성에 영향을 준다 [13]. 구리 전해 도금에 사용되고 있는 첨가제는 표면 단차와 표면 너울을 감소시켜 평탄한 도금표면층을 형성하도록 도와주는 평탄 제(leveler), 전착 속도를 억제하는 억제제(inhibiter, suppressor, carrier), 구리 전착 속도를 증가시키는 가속제(accelerator, brightener) 등으로 첨가제의 기능에 따라 분류 할 수 있다 [14,15]. 가속제로는 MPSA(3-mercapto-1-propane sulfonic acid), SPS(bis (3-sulfopropyl) disulfide), Thiourea(3N, Ndimethyl amino thio cabamoyl-1-sulfonic acid), DPS(3$\mathrm{N}, \mathrm{N}$-dimethylaminodithio carbamoyl-1-propane sulfonic acid) 등 유기 화합물로 알려져 있으며 [16-18], 억제제로는 Gelatin, 콜라겐, PEG(polyethylene glycol) 등의 중합체 계 열 유기 화합물이 대표적으로 사용된다 [19,20]. 평탄제는 JGB(Janus Green B), HEC (Hydroxyethyl Cellulose), 알 시안블루( $\mathrm{AB}, \mathrm{Alcian} \mathrm{Blue})$ 등 화합물이 주로 사용 된다 [21-24].

Park 등 [15]은 평탄제로 사용하는 첨가제 종류의 하나 인 $\mathrm{JGB}$ 를 $3 \mathrm{ASD}\left(\mathrm{A} / \mathrm{dm}^{2}\right)$ 의 낮은 전류밀도에서 연구한 결과 첨가량이 증가할수록 결정립 성장을 억제하여 미세한 결정구조를 보이고, 초기 면저항이 증가 한다하였다. Lee 등 [25]은 JGB, PEG 첨가량별 과전압 측정 시 첨가량 증가 시 과전압이 증가한 후 일정량 이상 첨가 시 과전압 이 감소함을 확인하였다. 또한 Jeong [23]은 JGB 첨가 시 결정립 크기가 감소하고 일정수준 이상의 첨가제가 첨가된 경우에는 self-annealing 수준의 열처리 조건에서는 재결정 이 이루어지지 않는다고 하였다. 이와 같은 대부분의 연구 들은 실제 조업조건과는 차이가 있는 $10 \mathrm{ASD}$ 이하의 낮 은 절류밀도에서 수행되었을 뿐만 아니라, 억제제와 평탄 제와의 조성비에 대한 상관관계 또한 규명되지 않았다. 또 한 JGB 첨가량에 따른 도금 진행과정에서의 전압의 변화, 도금층의 전기적 특성에 미치는 영향에 대한 연구가 요구 된다. 이에 본 연구에서는 높은 전류밀도에서 콜라겐과 $\mathrm{JGB}$ 첨가량에 따른 초기 핵생성과정에서의 분극현상과 이 러한 분극현상으로 인한 도금층의 표면 특성 및 결정구조 를 분석하였으며, 이러한 변화에 의하여 전기적 특성이 어
떻게 변화하는지에 대하여 파악하였다.

\section{2. 실험 방법}

본 연구에서 사용된 표 1 과 같이 황산 $\left(\mathrm{H}_{2} \mathrm{SO}_{4}\right)$-황산구리 $\left(\mathrm{CuSO}_{4} \cdot 5 \mathrm{H}_{2} \mathrm{O}\right)$ 전해액을 기본욕으로 제작하였다. 첨가제로 는 구리 도금공정에서 보편적인 사용되는 가속제 MPSA (3-mercapto-1-propane sulfonic acid)를 사용하였으며, 평 탄제로는 JGB (Janus Green B)를 사용하였다. 억제제는 콜라겐을 사용하였으며, 개별첨가제에 대한 첨가량 테스트 이후 염화이온과 $\mathrm{MPSA}$ 를 고정한 후 콜라겐과 $\mathrm{JGB}$ 의 첨 가량을 달리하여 테스트를 진행하였다. 양극으로는 불용성 양극(티타늄판위에 $\mathrm{IrO}_{2}$ 코팅)을 사용하였으며, 음극제로는 타이타늄판(99.9\%)을 \#1500까지 순차적으로 연마하여 사 용하였다. 개별첨가제의 첨가량에 따른 전압측정을 위하여 $1 \mathrm{~cm}^{2}$ 크기의 원형이 노출되도록 음극을 제조하였으며, 복 합적인 첨가제에 의한 전기적 특성 영향 평가를 위한 샘플 제작을 위하여 $50 \mathrm{~mm} \times 150 \mathrm{~mm} \times 1 \mathrm{~mm}$ 크기의 기판을 사용하였다. 도금이 이루어지는 음극과 양극의 거리는 $10 \mathrm{~cm}$ 로 일정하게 유지하였고, 도금이 진행되는 동안 전해 액의 온도는 $50{ }^{\circ} \mathrm{C}\left( \pm 0.5^{\circ} \mathrm{C}\right)$ 로 유지하였다. 도금은 정전류 모드 방식을 적용하여 $20 \mathrm{ASD}\left(\mathrm{A} / \mathrm{dm}^{2}\right)$ 전류밀도로 진행하 였으며, 물성분석을 위하여 도금층의 두께가 $12 \mu \mathrm{m}$ 되도 록 전착시켰다. 주사전자현미경(FESEM, SU-70, Hitachi, Japan)을 사용하여 도금층의 표면형상 관찰하였고 결정크기 및 결정구조를 분석하기 위하여 XRD (Dmax III-A type, Rigaku Co., Japan)장비를 사용하였다. 4극 탐침법(CMT$\mathrm{SR} 1000 \mathrm{~N}, \mathrm{AIT}, \mathrm{Korea})$ 장치를 사용하여 비저항을 측정 하 였다. 또한 도금층 및 기지층과의 접촉면의 표면조도 측정 을 위하여 표면조도측정기(SJ-400, Mitutoyo, Japan)를 활 용하여 표면의 $4.0 \mathrm{~mm}$ 길이를 측정하였다. 도금층의 비저 항, 표면조도 측정은 각각의 조건에서 2 회 재현 실험을 통 하여 시험편을 제작하여 3 회씩 총 6 회 측정하였다. 측정한 결과는 Minitab 프로그램을 사용하여 통계 처리하여 분석

Table 1. Chemical composition of electroplating baths.

\begin{tabular}{lc}
\hline \multicolumn{1}{c}{ Separation } & Composition \\
\hline Copper sulfate $\left(\mathrm{CuSO}_{4} \cdot 5 \mathrm{H}_{2} \mathrm{O}\right)$ & $0.79 \mathrm{M}$ \\
Sulfuric acid $\left(\mathrm{H}_{2} \mathrm{SO}_{4}\right)$ & $1.00 \mathrm{M}$ \\
Hydrochloric acid $(\mathrm{HCl})$ & $0 \sim 60 \mathrm{ppm}$ \\
Accelerator (MPSA) & $0 \sim 60 \mathrm{ppm}$ \\
Suppressor (Collagen) & $0 \sim 60 \mathrm{ppm}$ \\
Leveler (Janus Green B, JGB) & $0 \sim 60 \mathrm{ppm}$ \\
\hline
\end{tabular}


하였다.

\section{3. 결과 및 고찰}

개별첨가제의 농도를 달리하여 초기 전압을 측정하기 위 하여 0.2 초간 전해도금을 진행하였고, 전압변화가 안정화 된 $0.07 \sim 0.12$ 초 구간의 평균전압을 분석한 결과를 그림 1 에 나타내었다. 첨가제를 첨가하지 않은 조건 대비 첨가제 를 개별적으로 첨가한 군에서 전체적으로 전압이 높게 나 타나고 있다. 염화이온을 첨가한 경우 첨가량이 $10 ~ 20 \mathrm{ppm}$ 조건에서 무첨가 군 대비 전압이 높게 형성되었고 20 $\sim 40 \mathrm{ppm}$ 구간에서 전압이 감소한 이후 $40 \mathrm{ppm}$ 이상 조건 에서는 전압 변화가 현저히 감소하였다. 가속제인 MPSA 를 첨가한 조건에서는 $10 \mathrm{ppm}$ 첨가시 전압이 높게 형성되 나 $20 \sim 40 \mathrm{ppm}$ 첨가 시 전압이 감소한 이후 $60 \mathrm{ppm}$ 첨가 시 전압이 다시 증가하는 경향을 보이고 있다. 억제제인 콜라겐을 첨가한 경우에는 $10 \sim 30 \mathrm{ppm}$ 구간에서 전압이 급 격히 상승한 이후 감소하는 경향을 보이고 있다. 평탄제인 $\mathrm{JGB}$ 첨가제를 첨가한 경우에는 첨가량이 $10 \sim 30 \mathrm{ppm}$ 까지 증가되면서 전압이 증가한 이후 감소하는 경향을 보이고 있다. 이처럼 첨가제마다 첨가량에 따라 전압 상승구간이 다르며 안정된 역할을 수행하기 위하여 적절한 첨가제 첨 가가 필요할 것이다.

첨가제의 첨가 유무 및 첨가농도에 대한 테스트를 진행 하기 위하여 염화이온과 MPSA의 농도는 전압이 안정화된 $40 \mathrm{ppm}$ 의 농도를 선정하였고 콜라겐과 $\mathrm{JGB}$ 첨가량을 달 리하여 테스트를 진행하였다. 초기 전압과 도금층 표면을

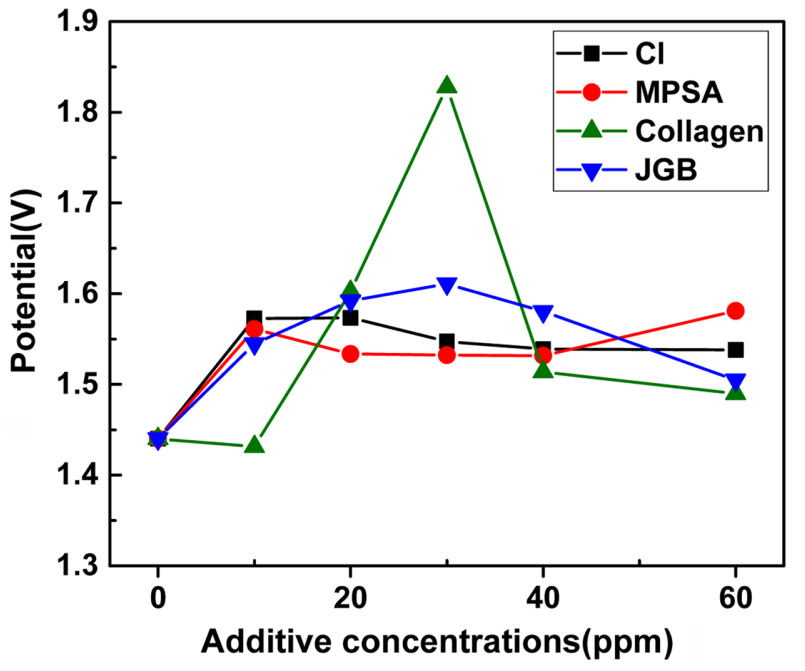

Fig. 1. Potential performance of the electrolyte at various additive with different concentrations.
Table 2. Potential and SEM images of copper plated for $12 \mu \mathrm{m}$ under various conditions

\begin{tabular}{|c|c|c|c|c|c|c|}
\hline & $\begin{array}{c}\mathrm{Cl} \\
(\mathrm{ppm})\end{array}$ & $\begin{array}{r}\text { MPSA } \\
(\mathrm{ppm})\end{array}$ & $\begin{array}{c}\text { Collagen } \\
\text { (ppm) }\end{array}$ & $\begin{array}{c}\text { JGB } \\
(\mathrm{ppm})\end{array}$ & $\begin{array}{c}\text { Potential } \\
\text { (V) }\end{array}$ & Surface images \\
\hline (a) & 0 & 0 & 0 & 0 & 1.440 & \\
\hline (b) & 40 & 40 & 0 & 0 & 1.580 & \\
\hline (c) & 40 & 40 & 20 & 0 & 1.583 & \\
\hline (d) & 40 & 40 & 20 & 10 & 1.663 & \\
\hline (e) & 40 & 40 & 20 & 30 & 1.671 & \\
\hline (f) & 40 & 40 & 30 & 0 & 1.662 & \\
\hline (g) & 40 & 40 & 30 & 10 & 1.690 & \\
\hline
\end{tabular}

분석한 결과를 표 2에 나타내었다.

개별 첨가제 테스트에서도 첨가제를 첨가한 경우에 초기 전압이 증가하였던 현상이 첨가제를 복합적으로 첨가한 경 우에도 동일하게 나타나고 있다. 그림 1 의 첨가제를 개별 첨가한 전압보다 염화이온과 MPSA를 $40 \mathrm{ppm}$ 씩 복합적으 로 첨가한 경우(b) 전압은 약 $40 ~ 50 \mathrm{mV}$ 증가하였고 무첨 가(a)군 대비 $140 \mathrm{mV}$ 의 전압상승이 있었다. 여기에 콜라겐 을 $20 \mathrm{ppm}$ 을 복합적으로 첨가한 경우(c) 전압 상승은 약 $3 \mathrm{mV}$ 로 변화도가 낮았다. 그러나 $\mathrm{JGB}$ 를 추가로 $10 \mathrm{ppm}$ 추가한 경우 $(\mathrm{d})$ 에는 약 $80 \mathrm{mV}$ 의 전압 상승으로 전압의 변 화도가 증가하였다. $\mathrm{JGB}$ 첨가량을 $10 \mathrm{ppm}$ 에서 $30 \mathrm{ppm}$ 으로 증가한 경우 약 $8 \mathrm{mV}$ 의 전압 상승으로 변화도는 미비하였 다. 억제제인 콜라겐을 $20 \mathrm{ppm}$ 첨가한 군 대비 $30 \mathrm{ppm}$ 첨가한 군에서는 $\mathrm{JGB}$ 첨가 여부와 관계없이 전압이 증가 


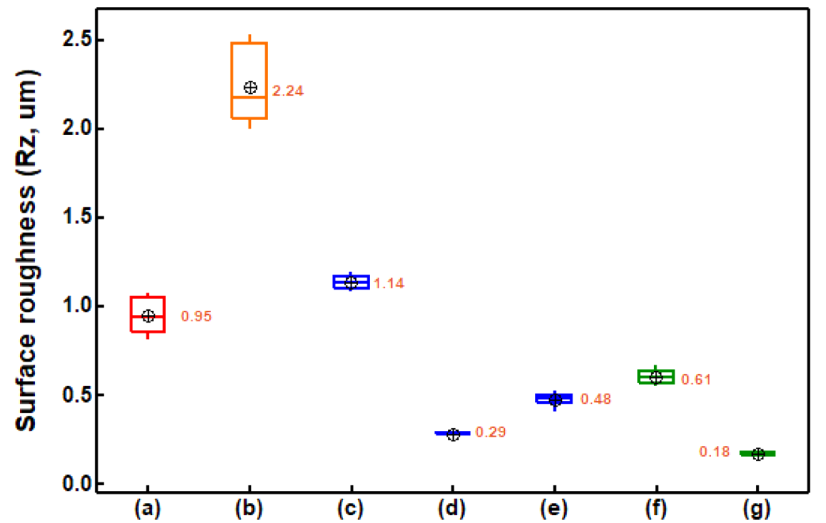

Fig. 2. Surface roughness of copper foil (matte layer) at the of various conditions.

하였다. 그러나 $\mathrm{JGB}$ 를 첨가한 $(\mathrm{g})$ 조건과 $(\mathrm{d})$ 조건의 전압 상승 대비 JGB를 첨가하지 않는 (f)조건과 (c)조건 비교 시 전압 상승폭은 감소하였다. $12 \mu \mathrm{m}$ 두께로 도금된 표면 층의 분석 결과를 보면 무첨가(a) 조건에서는 표면의 결정 들이 크게 존재하고 거친 형상을 보이고 있으며, 염화이온 과 $\mathrm{MPSA}$ 를 첨가한 조건에서는 표면에 $1 \mu \mathrm{m}$ 이상의 돌기 들이 존재하고 있다. 억제제인 콜라겐을 복합 첨가한 경우 표면에서의 결정의 크기는 감소하여 미세한 구조를 보이고 있으나, 표면이 평평하지 못한 형상을 보이고 있다. 평탄제 $\mathrm{JGB}$ 를 $10 \mathrm{ppm}$ 첨가한 $(\mathrm{d}),(\mathrm{g})$ 조건에서는 표면의 결정이 미세하며 평탄한 표면이 형성됨을 확인 할 수 있었다. 그 러나 $\mathrm{JGB}$ 를 $30 \mathrm{ppm}$ 첨가한 (e)조건에서는 표면이 균일하 지 못하고 부분적으로 거친 표면이 생성됨에 따라서 억제 제인 콜라겐을 $20 \mathrm{ppm}$ 첨가할 경우에는 $\mathrm{JBG}$ 첨가량은 $30 \mathrm{ppm}$ 미만으로 첨가하는 것이 적절하다 판단된다. 기존
연구결과[11]에서 콜라겐의 첨가량이 $60 \mathrm{ppm}$ 인 경우에는 $\mathrm{JGB}$ 의 첨가량이 $40 \mathrm{ppm}$ 이상 조건에서 이러한 현상이 나 타났다. 따라서 억제제와 평탄제의 조성비에 따라 표면 형 상에 미치는 영향이 큰 것으로 판단된다.

$12 \mu \mathrm{m}$ 두께로 도금한 표면의 거칠기를 관찰하기 위하여 측정한 결과를 그림 2에 나타내었다. 티타늄기지와 접촉한 면의(S면, shiny면) 표면조도(Rz)는 $0.77 \mu \mathrm{m}$ 로 모든 조건 에서 동일하게 나타나고 있으며, 구리가 전착되면서 첨가 제의 영향으로 최종 도금층의 표면의 거칠기가 변화하였다. 첨가제를 첨가하지 않은 (a)조건과 염화이온, MPSA를 첨 가한 (b)조건 그리고 콜라겐을 추가적으로 $20 \mathrm{ppm}$ 첨가한 (c)조건의 표면조도는 티타늄 기지와의 접촉면(S면) 대비 표면조도가 증가하였다. 그러나 콜라겐을 $30 \mathrm{ppm}$ 첨가한 (f)조건은 표면조도(Rz: $0.61 \mu \mathrm{m})$ 는 $\mathrm{S}$ 면 대비 감소하였다. 도금면(M면, matte면)의 표면조도 감소 효과가 가장 높은 것은 평탄제인 $\mathrm{JGB}$ 첨가제를 첨가한 경우로 $10 \mathrm{ppm}$ 첨가 한 $(\mathrm{d})$ 조건과 $(\mathrm{g})$ 조건의 경우 무첨가 대비 약 $25 \sim 30 \%$ 수 준으로 감소하였다. 일반적인 평탄제와 억제제의 거동을 살 펴보면, 음극표면에서 표면에너지가 높은 edge, nodule 그 리고 needle에서 첨가제가 흡착되게 된다. 극성을 띄고 있 는 억제제와 평탄제는 표면에너지가 높은 곳에서 isolating layer를 형성하여 표면에너지를 감소시킨다. 따라서 needle 이 성장하는 것을 방지하고 평탄화가 이루어진다. 그러나 이러한 반응은 짧은 시간 동안 이루어지며, 다른 부분의 표면층의 높이가 needle의 높이와 비슷해지거나, 또 다른 높은 표면에너지 영역이 발생되면 이동하여 흡착한다 [26]. 또한 이러한 과정이 반복적으로 이루어지면서 표면 거치기 를 감소시킨다. 산업용 이차전지 음극재료로 사용하기 위 해서는 표면 조도가 $1 \mu \mathrm{m}$ 이하의 조건을 만족하여야 한다.
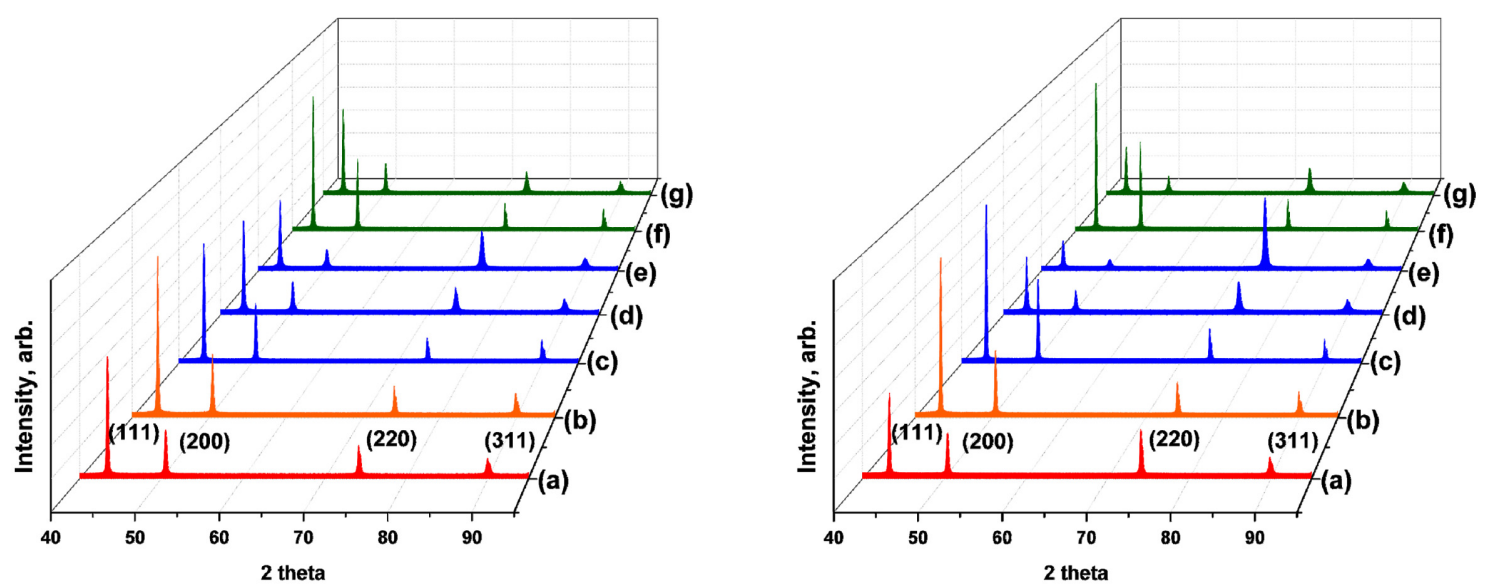

Fig. 3. XRD analysis of copper layer with various additives concentrations in bath solutions (left: shiny layer, right: matte layer). 

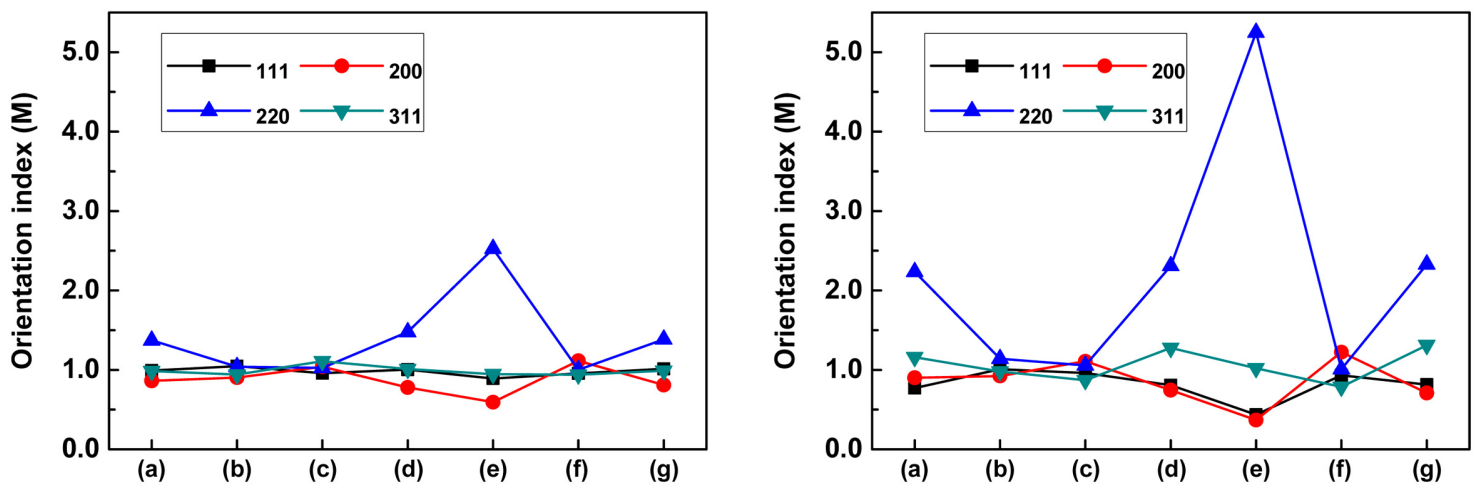

Fig. 4. Orientation index (M) of copper layer with various additives concentrations in bath solutions (left: shiny layer, right: matte layer).

따라서 억제제 또는 평탄제를 적절히 첨가하여 도금층의 표면조도 제어가 필요하다.

첨가제에 의한 도금층의 결정구조 변화에 대하여 관찰하 기 위하여 XRD 분석을 진행하였으며 측정결과를 그림 3 에 나타내었다. $\mathrm{S}$ 면과 $\mathrm{M}$ 면의 경향성의 큰 차이는 없으나, $\mathrm{JGB}$ 를 $30 \mathrm{ppm}$ 첨가한 (e)조건의 경우 $\mathrm{S}$ 면 대비 $\mathrm{M}$ 면에서 (220)방위의 피크가 다른 방위보다 높게 형성이 되어 면간 의 변화가 두드러지게 나타나고 있다. $\mathrm{S}$ 면의 경우 첨가제 유무와 관계없이 (111)방위의 피크가 가장 높게 나타나고 있으며, JGB의 첨가로 인하여 (111)방위의 피크가 감소하 고 (220) 방위의 피크가 증가하는 경향을 보이고 있다. 또 한 이러한 경향은 $\mathrm{M}$ 면에서 더 활발하게 일어나고 있다. 평탄제의 효과는 초기 핵생성단계에서도 나타나고 있으나 결정이 성장하는 과정에서 더 두드러지게 나타나고 있다.

결정성장 방위에 대하여 좀 더 구체적인 분석을 위하여 orientation index(M) 분석법을 Yoshimura [27] 등이 제안 하였고 이를 이용하여 그림 4에 나타내었다. 우선 성장 방 위를 분석한 결과 모든 조건에서 $\mathrm{S}$ 면 대비 $\mathrm{M}$ 면에서 (220)결정방위로 결정들이 우선 성장하려는 경향이 나타나 고 있으며, JGB를 $30 \mathrm{ppm}$ 첨가한 (e)조건에서 (220) 결정 방위로 성장하려는 경향이 $\mathrm{S}$ 면과 $\mathrm{M}$ 면의 편차가 두드러지 게 나타나고 있다. $\mathrm{S}$ 면의 경우 염화이온과 $\mathrm{MPSA}$ 를 첨가 한 (b)조건과 콜라겐을 복합적으로 첨가한 (c)조건과 (f)조 건의 경우 모든 방위에서 $0.90 \sim 1.22$ 로 1 에 근접한 값을 보이고 있어, 여러 방위로 결정들이 성장하는 경향을 보이 고 있다. 그러나 도금이 진행되는 동안 첨가제의 영향으로 우선성장 방위의 변화가 이루어지고 있다. 억제제인 콜라 겐을 첨가한 경우(c군, f군) (200) 방위로 우선 성장하려는 경향을 보이고, $\mathrm{JGB}$ 를 첨가한 경우(d군, e군, $\mathrm{g}$ 군)에는 (220)방위와 (311)방위로 우선 성장하려는 경향을 보이고
있다. Gittis [27]등은 $\mathrm{FCC}$ 구조의 구리는 각 면간의 표면 에너지는 (220)면이 가장 높고, (200), (111) 순으로 감소 된다 하였다. 이러한 현상은 음극 표면에서의 구리가 전착 될 때 원자들의 이동이 원활하지 않는 조건에서 높은 표면 에너지를 갖는 면으로 우선 배향 된다 하였다. 평탄제는 표면에서 에너지가 높은 곳에 흡착되어 성장을 억제하면서 구리 이온의 표면이동을 방해하게 하게 한다. 결과적으로 구리이온이 표면에서 (220) 방위에 평행하게 전착하게 한 다. 또한 Lee 등 $[29,30]$ 과 Yang 등 [30]은 구리는 $\mathrm{FCC}$ 결정구조를 가지며 결정이 가장 치밀한 (111)면으로 성장 하는 경우에 (200)방위로 성장하는 결정에 비하여 일반적 으로 electro migration(EM) 저항성이 우수하다 하였다. 또한, $\mathrm{EM}$ 이 입계확산을 통해 주도적으로 발생되는데, 결 정립이 (111)방위로 배향 되었을 때 가장 효과적으로 입계 확산계수를 낮출 수 있고, 이로 인하여 $\mathrm{EM}$ 에 대한 내성이 커질 것이라 하였다. 따라서 (220) 방위로 성장하려는 경 향이 강할수록 $\mathrm{EM}$ 에 대한 내성은 작아지기에 JGB 첨가 량을 낮추는 조건을 도출하는 것이 필요하다.

Scherrer식으로 알려져 있는 다음 식(1)을 이용하여 결정 립 크기 t를 구하였고 [32,33], 이 결과를 그림 5에 나타내 었다. 여기서 $\lambda$ 는 $\mathrm{X}$ 선 회절분석 장비에서 사용되는 구리 타겟은 $0.154056 \mathrm{~nm}$ 의 파장을 가지며, $\theta$ 는 회절피크의 위 치의 $2 \theta$ 의 반절인 값이다. $\mathrm{B}$ 는 시편에서 각각 측정된 피 크의 반가폭을 이용하여 구하였다.

$$
t=\frac{0.89 \bullet \lambda}{B \bullet \cos \theta}
$$

평탄제인 $\mathrm{JGB}$ 첨가제를 첨가한 조건을 제외하고는 $\mathrm{S}$ 면 대비 $\mathrm{M}$ 면에서 모든 결정방위에서 결정립의 크기가 증가하 는 현상을 보였고, 특히 콜라겐을 첨가한 조건에서 결정립 

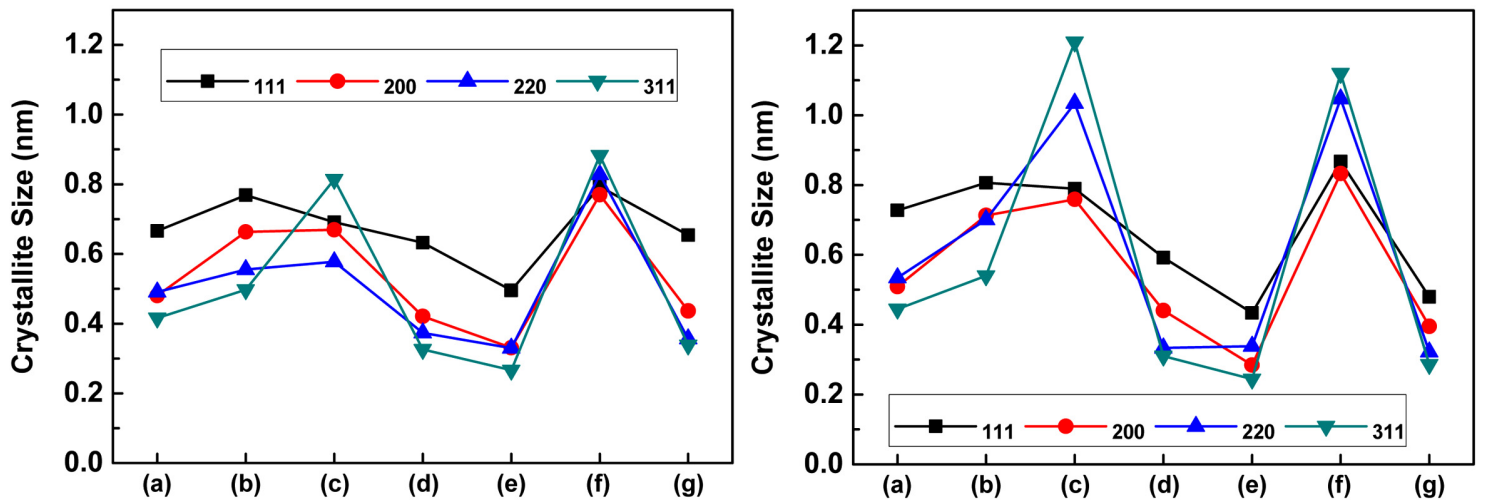

Fig. 5. Crystallite size evolution of electroplated copper layer with additives concentrations in the solutions (left: shiny layer, right: matte layer).

의 크기 증가가 두드러지게 나타나고 있다. JGB를 첨가한 조건에서는 $\mathrm{S}$ 면 대비 $\mathrm{M}$ 면의 결정립 크기가 감소하였다. 도금 표면층의 결정립 크기의 경우 첨가제를 첨가하지 않 은 (a)조건 대비 JGB를 복합적으로 첨가한 $(\mathrm{g})$ 조건의 경우 모든 방위에서 $10 \sim 27 \%$ 결정립 크기가 감소하였다. 평탄제 는 억제제와 마찬가지로 도금을 억제하기 위해 도금 표면 에 흡착하게 된다. 평탄제는 이러한 흡착능력이 촉진제, 억 제제보다 강하다고 하였다 [15,34-37]. 그러나 이러한 강한 흡착력은 도금 내에 첨가제가 쉽게 매몰 될 수 있을 것으 로 판단된다. 따라서 강한 흡착력으로 인하여 도금층 내부 의 첨가제가 흡착되어 내부 불순물 농도가 높아질 수 있다. Park 등 [15]의 연구에 따르면 농도를 달리하여 JGB를 첨 가하였을 때 첨가제의 농도가 높아질수록 도금층 내부의 불순물의 농도가 선형적으로 증가하였고 이로 인해 도금층 형성 후 결정립 성장이 억제된다 하였다. 그러나 이러한 불순물의 농도 증가는 전기적 특성에 문제가 될 수 있다.

첨가제의 의한 전기적 특성 변화를 관찰하기 위하여 비 저항을 측정한 결과를 그림 6 에 나타내었다. 먼저 조도의 영향을 배제하기 위하여 동일한 조도를 갖는 티타늄 기지
와의 접촉면을 $(\mathrm{S}$ 면) 기준으로 비저항을 측정한 결과 무첨 가(a), 염화이온과 MPSA를 첨가한 조건(b) 및 (c), (f)조 건의 비저항은 통계학적으로 유의차(p-value: 0.130)가 없 었다. 평탄제인 JGB첨가제를 첨가한 $(\mathrm{d}),(\mathrm{e}),(\mathrm{g})$ 조건의 경우에는 비저항이 무첨가 조건 대비 $15.7 \sim 19.7 \%$ 증가하 였다. 도금면(M면)의 경우 (a), (b) 조건을 제외한 다른 조 건에서는 도금 초기에 형성된 $\mathrm{S}$ 면의 비저항과 비슷한 경 향을 가지고 있다. 염화이온과 MPSA를 첨가한 (b)조건의 경우 $\mathrm{S}$ 면 대비 비저항이 약 $15.5 \%$ 증가하였다. 이러한 원 인으로는 그림 2 의 표면도조 결과와 같이 $\mathrm{S}$ 면 대비 $\mathrm{M}$ 면 의 표면조도가 약 $190 \%$ 증가한 원인으로 판단되며 이러 한 결과는 Kuan [38] 등에 제시한 비저항 계산식에서 표 면 거칠기가 증가하면 비저항은 비례하여 증가한다는 결과 와 일치한다. 또한 첨가제를 첨가하지 않은 (a)조건의 경우 $\mathrm{S}$ 면 대비 $\mathrm{M}$ 면의 표면조도의 변화는 $23.4 \%$ 증가로 $(\mathrm{b})$ 조 건 대비 증가폭은 크지 않았으나, 비저항이 증가하여 (b)조 건과 유사한 비저항 값을 보이고 있다. 이러한 비저항의 변화의 원인은 초기 결정면인 $\mathrm{S}$ 면 대비 $\mathrm{M}$ 면의 결정성장 이 우선 성장방위 (220)면에 평행하게 성장되었기 때문이
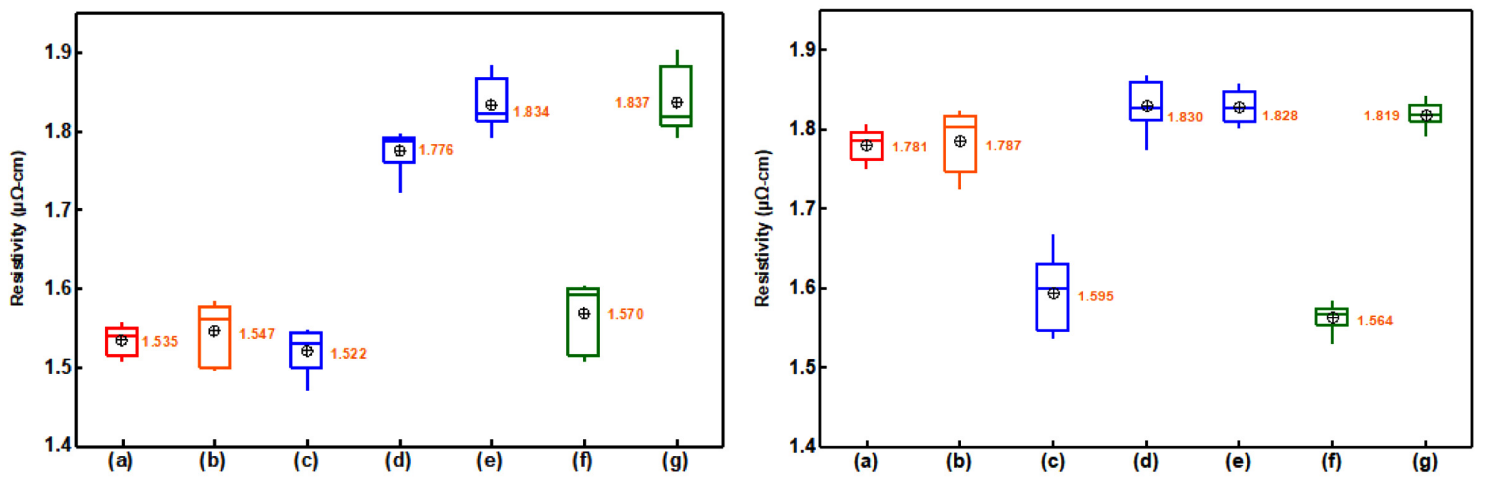

Fig. 6. Resistivity of electroplated copper layer with additives concentrations in the solutions (left: shiny layer, right: matte layer). 
다. 또한 (220)면의 결정립 크기의 증가 경향을 볼 때 (a) 조건 대비 (b)조건의 증가폭이 크기 때문에 결정립의 크기 변화와 결정성장 방위의 복합적인 영향으로 비저항이 비슷 한 경향을 보인 것으로 판단된다. $\mathrm{JGB}$ 를 첨가한 $(\mathrm{d}),(\mathrm{e})$ 그리고 $(\mathrm{g})$ 조건의 경우 결정립 우선성장 방위가 $(220)$ 방위 로 무첨가 대비 결정성장 면적의 증가로 비저항이 증가되 었으며, 결정립의 크기 또한 감소하였다. 결정립 크기가 나 노사이즈인 경우 경계면의 비탄성산란으로 인하여 비저항 이 증가하게 된다고 하였다 [39]. 따라서 결정성장 방위와 결정립의 크기 변화에 의한 복합적인 영향으로 비저항이 증가한 것으로 판단된다. 그러나 $\mathrm{JGB}$ 첨가량 및 콜라겐 첨가량에 따른 비저항 변화는 유의차가 없었다(p-value: 0.717).

\section{4. 결 론}

고전류밀도 전해도금 공정에서 억제제와 평탄제 첨가에 의한 표면특성, 구조적 특성 및 전기적 특성을 확인하기 위하여 콜라겐과 $\mathrm{JGB}$ 의 양을 변화시켜 첨가한 후 도금층 에 대한 연구를 진행하였다.

1. 첨가제를 개별적으로 첨가한 결과 첨가제에 따라 전 압을 상승시키는 첨가량이 달랐으며, 콜라겐을 $30 \mathrm{ppm}$ 첨 가한 경우 첨가제를 첨가하지 않은 무첨가 조건 대비 약 $27 \%$ 높은 전압을 보이고 있다.

2. 첨가제를 복합적으로 첨가한 경우 억제제를 투여하지 않는 조건에서는 무첨가 조건대비 표면조도가 약 $136 \%$ 증 가하여 표면조도(Rz) $2.24 \mu \mathrm{m}$ 로 최대치를 보였다. 콜라겐 $30 \mathrm{ppm}$ 이하 및 $\mathrm{JGB} 10 \mathrm{ppm}$ 조건에서 $0.3 \mu \mathrm{m}$ 이하의 표면 거칠기를 가진 균일한 도금층을 형성할 수 있었다.

3. 가속제와 억제제를 첨가한 경우 도금이 진행되는 과 정에서 결정립의 크기가 증가되는 현상을 보이고 평탄제를 추가적으로 첨가한 경우 결정립을 감소시키는 경향을 보이 고 있다.

4. JGB를 첨가한 경우 (220) 방위로 결정이 우선성장하려 는 경향이 증가되며, 결정립 크기를 무첨가 대비 $10 ~ 27 \%$ 감소시키는 효과가 나타났다.

5. 억제제인 콜라겐을 첨가한 경우 $\mathrm{S}$ 면과 $\mathrm{M}$ 면의 비저항 의 편차를 줄일 수 있었으나, 결정립의 크기 편차가 발생 되고 있다. 이를 개선하기 위해서는 평탄제인 JGB를 첨가 가 필요하다.

본 연구를 통하여 표면조도가 낮고 균일한 도금층을 형 성하며 $\mathrm{S}$ 면과 $\mathrm{M}$ 면의 구조적인 편차가 적은 구리 도금층 을 형성하기 위해서는 가속제, 억제제 및 평탄제가 적절하
게 첨가되어야 함을 확인 할 수 있었다. 첨가제를 많이 첨 가한 경우 도금층의 첨가제 혼입에 대한 문제점을 야기 할 수 있기에 적은량의 첨가제의 첨가량 도출이 필요하다. 따 라서 본 연구에서는 콜라겐의 첨가량이 $30 \mathrm{ppm}$ 이하의 조 건에서 $\mathrm{JGB}$ 첨가제는 $10 \mathrm{ppm}$ 을 첨가한 조건에서 표면이 균일한 도금층이 형성됨을 확인 할 수 있었다.

\section{REFERENCES}

1. M. H. Kim, H. R. Cha, C. S. Choi, J. M. Kim, and D. Y. Lee, Korean J. Met. Mater. 48, 884 (2010).

2. S. H. Kim, D. H. Shin, Y. S. Choi, J. G. Kim, and S. H. Kim, J. Kor. Inst. Met. \& Mater. 43, 538 (2005).

3. T. G. Woo, Korean J. Met. Mater. 54, 681 (2016).

4. S. W. Lee, Master Thesis(in Korean), pp.1-2, Jeonbuk National University, Jeonbuk (2015).

5. C. C. Hu and C. M. Wu, Surf. Coat. Technol. 176, 75 (2003).

6. V. S Donepudi, R. Venkatachalapathy, P. O. Ozemoyah, C. S. Johnson, and J. Prakash, Electrochem. Solid-state. Lett. 4, C13 (2001).

7. Y. K. Lee and T. J. O'keefe, JOM, 54, 40 (2002).

8. P. V. Brande and R. Winand, Surf. Coat. Technol. 52, 1 (1992).

9. Z. Zhou and T. J. O'Keefe, J. Appl. Electroch. 28, 461 (1998).

10. M. L. Sartorelli, A. Q. Schervenski, R. G. Delatorre, and P. Klauss, Phys. Stat. Sol. 187, 91 (2001).

11. T. G. Woo and I. S. Park, Korean J. Met. Mater. 58, 41 (2020).

12. J. J. Yang, Y. L. Huang, and K. W. Xu, Surf. Coat. Technol. 201, 5574 (2007).

13. V. A. Vas'ko, I. Tabakovic, S. C. Riemer, and M. T. Kief, Micro. Engn. 75, 71 (2004).

14. H. C. Kim and J. J. Kim, Kor. Chem. Eng. Res. 54, 723 (2016).

15. C. M. Park, U. H. Lee, and H. J. Lee, Korea J. Met. Mater. 54, 469 (2016).

16. S. K. Kim and J. J. Kim, Electrochem. Solid-State Lett. 7, C98 (2004).

17. S. K. Cho, S. K. Kim, and J. J. Kim, J. Electrochem. Soc. 152, C330 (2005).

18. S. Choe, M. J. Kim, H. C. Kim, S. K. Cho, S. H. Ahn, S. K. Kim, and J. J. Kim, J. Electrochem. Soc. 160, D3179 (2013).

19. M. H. Kim, H. R. Cha, C. S. Choi, H. S. Kim, and D. Y. Lee, 
Korean J. Met. Mater. 48, 757 (2010).

20. J. W. Gallaway, M. J. Willey, and A. C. West, J. Electrochem. Soc. 156, D287 (2009).

21. Y. Cao, P. Taephaisitphongse, R. Chalupa, and A. C. West, J. Electrochem. Soc. 148, C466 (2001).

22. S. K. Kim, D. Josell, and T. Moffat, J. Electrochem. Soc. 153, C616 (2006).

23. Y. H. Jeong, Master Thesis(in Korean), pp.11-40, Dong-A University, Busan (2016).

24. T. G. Woo, J. J. Park, and I. S. Park, Korean J. Met. Mater. 59, 304 (2021).

25. M. H. Lee and J. K. Cho, J. Kor. Inst. Surf. Eng. 46, 153 (2013).

26. P. Stantke, JOM, 54, 19 (2002).

27. S. Yoshimura, S. Yoshihara, T. Shirakashi, and E. Sato, Electrochim. Acta, 39, 589 (1994).

28. A. Gittis and D. Dobrev, Thin solid Films, 130, 335 (1985).

29. H. S. Lee, H. S. Kim, and C. M. Lee, J. Kor. Inst. Met. \& Mater. 39, 920 (2001).

30. H. S, Lee, D. K. Kwon, H. A. Park, and C. M. Lee, Kor. J. Mater. Res. 13, 174 (2003).
31. C. H. Yang, S. C. Lee, J, M. Wu, and T. C. Lin, Appl. Surf. Sci. 252, 1818 (2005).

32. B. D. Cullity and S. R. Stock, Elements of X-ray diffraction, third ed., p.170, Pearson Education, New Jersey (2001).

33. S. H. Lee and N. J. Park, J. Kor. Inst. Met. \& Mater. 44, 556 (2006).

34. I. S. Kang, Y. S. Koo, and J. H. Lee, J. Microelectron. Packag. Soc. 19, 67 (2012).

35. Q. Huang, A. Avekians, S. Ahmed, C. Parks, B. BakerO'Neal, S. Kitayaporn, A. Sahin, Y. Sun, and T. Cheng, J. Electrochem. Soc. 161, D388 (2014).

36. J. Kelly, T. Nogami, O. van der Straten, J. Demarest, J. Li, C. Penny, T. Vo, C. Parks, P. Dehaven, C. K. Hu, and E. Liniger, J. Electrochem. Soc. 159, D563 (2012).

37. S. H. Jin, D. R. Lee, W. Y. Lee, S. Y. Le, and M. H. Lee, Met. Mater. Int. 21, 775 (2015).

38. T. S. Kuan, C. K. Inoki, G. S. Oehrlein, K. Rose, Y. P. Zhao, G. C. Wang, S. M. Rossnagel, and C. Cabral, Mater. Res. Soc. Symp. Proc. 612, D7.1.1 (2000).

39. S. H. Huh, H. J. Jeon, H. S. Chu, Y. S. Song, S. K. Lee, H. J. Lee, and U. H. Lee, Korea J. Met. Mater. 52, 943 (2014). 